\title{
Small maternity units: GMSC sends report to Minister
}

In 1979 the Conference of Representatives of Local Medical Committees passed a resolution objecting to GP maternity units being closed without alternative GP maternity beds being provided. The subject had been discussed with Departmental officials, and the Minister of Health, Dr Gerard Vaughan, asked the General Medical Services Committee's representatives to prepare a paper. The paper, reproduced here, has been approved by the GMSC's Maternity Services Subcommittee and the chairman of the GMSC and forwarded to the Minister.

Small maternity units can be defined conveniently as those with fewer than 500 births a year. Most of them are served by general practitioners and many were in existence before the Health Service. Their numbers have slowly dwindled over the years until today only about 150 remain. The factor most influencing this decline has been the development of large obstetric units in district hospitals with full-time medical staff. Designed originally to provide an improved alternative to home confinement, these units have, for the past 20 years, also replaced the small maternity unit in many areas.

The watershed year was 1958. By 1958 it was apparent that the progress made in the large hospital units had not been matched by equivalent progress in the small units. The work of Butler ${ }^{1}$ and his colleagues on behalf of the National Birthday Trust demonstrated clearly that perinatal mortality in general practice had not fallen as rapidly and was equally bad whether the mother was confined in a small unit or in the home. The large unit with full-time staff had come to provide a doctor-oriented service while the small unit had continued with a service largely managed by midwives. Antenatal care was minimal and case selection almost non-existent. Small units were ill equipped and naturally enough mothers getting into difficulties had considerably less chance than mothers who had chosen to book into the large unit. At much the same time the report of the Cranbrook Committee $^{2}$ led to changes in the fees paid for maternity care which did nothing to encourage general practitioners to continue responsibility for confinements. The proportional relationship of the various fees established in 1961 remains the same today.

These two factors combined at the time to persuade many general practitioners to abandon intrapartum obstetrics and have been joined in the intervening years by a third. Based on the findings of the 1958 perinatal mortality survey ${ }^{3}$ and reinforced by the recommendations of the Peel report, ${ }^{4}$ orthodox training in obstetrics at undergraduate and postgraduate level has promoted the doctrine that safety for the mother and child can only be achieved within the curtilage of a large obstetric unit. Since 1970 it has been the view of the DHSS also that "births should be concentrated in larger fully equipped and properly staffed consultant units of district general hospitals. Where circumstances permit small, underused, and isolated maternity units should be closed."

Meanwhile, general practitioners have reevaluated their standards of obstetric practice. The vast majority providing intrapartum care regularly do so in small units. Many have improved the standards and equipment of their units with funds from both charitable and official sources. Many have formed close links with consultant colleagues and have effectively become satellites of nearby large hospital units. Many have modified the midwife-based service with a greater doctor involvement at the confinement and have established a true partnership with midwifery colleagues. Some have done all of these things.

\section{Art of case selection}

The most important factor, however, has been the gradual development and refinement of the art of case selection. It is probably true to say that at the time of the 1958 survey the place of confinement was largely determined by the mother, whereas nowadays, a few home confinements apart, this is decided on medical

Some GP unit statistics

\begin{tabular}{|c|c|c|c|c|c|c|}
\hline GP unit & Deliveries & $\begin{array}{l}\text { Perinatal } \\
\text { deaths }\end{array}$ & $\begin{array}{l}\text { Transfers } \\
\text { in labour }\end{array}$ & $\begin{array}{c}\text { Perinatal } \\
\text { deaths }\end{array}$ & $\begin{array}{c}\text { Trarisferred } \\
\text { babies }\end{array}$ & $\begin{array}{l}\text { Perinatal } \\
\text { deaths }\end{array}$ \\
\hline Trowbridge Hospital, 1978 & 713 & 0 & 67 & Not known & & 1 \\
\hline $\begin{array}{l}\text { Trowbridge Hospital, } 1979 \\
\text { Mary Stevens Maternity Home, }\end{array}$ & 705 & 0 & 72 & Not known & Not known & 3 \\
\hline $\begin{array}{l}\text { Stourbridge, } 1976 \\
\text { Mary Stevens Maternity Home, }\end{array}$ & 530 & 1 & 81 & Not known & Not known & Not known \\
\hline $\begin{array}{llll}\text { Stourbridge, } 1977 & \cdots\end{array}$ & 502 & 1 & 66 & Not known & 18 & Not known \\
\hline $\begin{array}{l}\text { ks Hospital, } 1977 \quad \ldots \\
\text { ks Hosnitiol }\end{array}$ & $\begin{array}{l}279 \\
331\end{array}$ & 0 & 29 & & 23 & \\
\hline $\begin{array}{l}\text { ks Hospital, } 1976 \\
\text { y House, Exeter, } 1977\end{array}$ & $\begin{array}{l}331 \\
311\end{array}$ & $\begin{array}{l}0 \\
0\end{array}$ & 36 & $\begin{array}{c}\text { Not known } \\
0\end{array}$ & $\begin{array}{l}28 \\
\text { Not known }\end{array}$ & $\begin{array}{l}\text { Not known } \\
\text { Not known }\end{array}$ \\
\hline 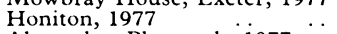 & & 0 & 8 & 0 & & Not known \\
\hline $\begin{array}{l}\text { Alexandra, Plymouth, } 1977 \text { : } \\
\text { Brixham, } 1977 . .\end{array}$ & $\begin{array}{l}515 \\
113\end{array}$ & 1 & $\begin{array}{r}177 \\
7\end{array}$ & $\begin{array}{l}0 \\
0\end{array}$ & $\begin{array}{l}\text { Not known } \\
\text { Not known }\end{array}$ & $\begin{array}{l}\text { Not known } \\
\text { Not known }\end{array}$ \\
\hline $\begin{array}{l}\text { Brixham, } 1977 ., 1977 \ldots \\
\text { Newton Abbot, } 1977\end{array}$ & 31 & 1 & 25 & Not known & $\begin{array}{l}\text { Not known } \\
\text { Not known }\end{array}$ & Not known \\
\hline $\mathrm{H}$ & 21 & 0 & 49 & Not known & 7 & 0 \\
\hline 的 19 & & 0 & & 0 & 6 & 0 \\
\hline $\begin{array}{l}\text { Harpenden, } 1979 \\
\text { North Walsham, Norfolk, } 1980\end{array}$ & $\begin{array}{l}188 \\
166\end{array}$ & $\begin{array}{l}0 \\
0\end{array}$ & $\begin{array}{l}29^{*} \\
14\end{array}$ & $\begin{array}{l}0 \\
0\end{array}$ & $\begin{array}{l}4 \\
5\end{array}$ & $\begin{array}{l}0 \\
0\end{array}$ \\
\hline
\end{tabular}

*Including 21 for lack of midwifery staff.

advice. With the assistance and encouragement of enlightened consultant colleagues case selection and intrapartum transfer criteria are sufficiently advanced to take full account of the potential hazards to the mother and the baby at every stage, and the results published by some units are beyond improvement. In 1979 the annual meeting of the BMA resolved "That GP intrapartum obstetrics no longer merits the condemnation it received following the perinatal mortality survey of 1958." Finally, there is statistical confusion allowing everyone to select evidence to suit a particular point of view. Papers have appeared supporting, on statistical evidence, every venue for the confinement. Refutations, based on different statistics, have been followed by counter refutations and it is no longer possible to be certain of the true facts. In any case the material from 1958 and 1970 on which most papers are based is quite out of date from the point of view of GP case selection techniques and involvement at the confinement in 1980 .

The GMSC itself has for several years invited GP units to present reports annually as a guide to work load and standards of current practice. Many of these contain extremely useful information, but not everything that would be of most value is always there. Most reporting units identify transfers in labour but often with no account of the perinatal outcome. There are very few reports about babies transferred for paediatric care. Enough information is available, however, and examples of some of the best returns are given in the table. Although many are incomplete, they give a clear indication of the standards currently achieved.

Sadly, units such as these face closure threats at local level just as frequently as those with poorer returns and those which are underused. This pressure has intensified in recent years as the birth rate has fallen and already there are areas where units have been closed which have insufficient beds to meet the currently rising demand. Health authorities will often begin by questioning the safety of a unit. This has happened to at least one unit which has had a perinatal mortality rate of nil for three consecutive years covering not only babies born in the unit but also those born following transfer in labour to a consultant unit and those transferred after delivery to a paediatric unit. Sometimes the unit is declared to be too expensive, although health authorities can seldom produce sound economic reasons with figures to support this approach. Finally, the argument comes to rest behind "the policy closure if they are small or if they are underused or if they are isolated. "Isolated" is the usual reason. Certainly in the eyes of most for a unit to be all three of these things, and to that extent the Department's policy is being misinterpreted.

Much of this activity is directed towards serving the Department's objective of concentrating births in large consultant units of district general hospitals. Many reports of regional and area working parties on obstetrics and paediatrics, on which general practitioners seldom have a place, are currently recommending that $100 \%$ of births should take place in such units. The GMSC is unable to support this policy as there can no longer be any evidence that for suitable cases they are any safer than at least some GP units. Further, the more we move towards $100 \%$ large-unit confinement the less expertise is available to deal with the few remaining mothers who insist on a home confinement, an area in which we already face many problems. Also, if safety in certain units is no longer a question the small units' attraction for mothers on the grounds of proximity, personal service, and a homely atmosphere is difficult to resist. Even so, the GMSC would not support the retention of small units which are underused and consuming resources which could be deployed to better effect elsewhere.

What then is to be done? Firstly, much more information is needed of a kind which is standardised so that statistical analysis can be comparative and cover areas such as transfers continued on page 839 authorities it does not seem to be necessary 


\title{
Audit in general practice: joint GMSC/RCGP letter
}

\author{
LMCs and college faculties urged to liaise
} held on audit in general practice. This was sponsored jointly by the General Medical Services Committee and the Royal College of General Practitioners and was attended by 170 medical representatives of local medical committees and honorary secretaries of RCGP faculties (22 November 1980, p 1440). The chairman of the GMSC, Dr John Ball, and the chairman of the RCGP Council, Dr A G RCGP faculties about the conclusions and recommendations of the liaison committee that RCGP to advise the profession on how to proceed with the concept of medical audit in general practice. Their letter is reproduced here.

\section{Chairmen's joint letter}

Audit begins at home, and as professional people we all review and assess our work and performance. For a number of reasons many now recognise the need for some sharing in the task of review and improvement in the methods involved. Everyone seems to recognise the inevitable differences between doctors and practices which mean that there can be no universal or stereotype of audit. Many local groups of doctors do have a great deal in common, including the population they serve and the services they use. This gives them a significant basis for helpful comparison.

The current task is to identify what is already happening, encourage the formation and development of local groups, and to outline for these groups the range of opportunities that exist for study.

Common to all methods of audit is the need to repeat the exercise after an interval to determine whether there has been any improvement. As a result of such study, action should be able to follow which will improve outcome, or alternatively confirm that no further action is needed at the present time.

The liaison committee is aware of the
In November 1980 a one-day symposium was Donald, have now written to LMCs and was set up between the GMSC and the

benefit of co-operation and collaboration in fields of mutual interest to the GMSC and the college; it recommends that such liaison should be established at local level in the field of medical audit, with the common aim of establishing rapport with general practitioners in the area concerned, especially with those doctors who seek to preserve thei rights to have nothing to do with formal methods of audit. The liaison committee considers that the best way in which this could be done would be to ask LMCs and faculties jointly to nominate a colleague or colleagues who will have the tasks of identifying methods of audit already taking place within each NHS district, and disseminating information about available methods of audi which are taking place both within the area and elsewhere to the local general practitioners.

Where small discussion groups already exist, examining the performance of their individual members, and the supporting services that they rely upon, the doctors involved appear to have been successful in establishing audit techniques. It is suggested that the setting up of such discussion groups would be a reasonable practical step to take, which could be stimulated by the jointly nominated colleague or colleagues, where no method of audit already exists. If the succes of such groups can be put across, it is likely that the majority of general practitioners wil eventually be convinced that the ideas are worth putting into practice, and implementing as routine.

The liaison committee very much hopes that joint action locally will lead to the involvement of as many general practitioners as possible in audit exercises. It is recommending to the GMSC and the college that the development of medical audit in general practice must be reviewed, and considers itself to be the ideal group to carry out thi monitoring function, and to feed back information. We need, therefore, to know what progress is being made in the field of audit following the November symposium, and especially henceforth; we hope your committee or faculty will co-operate in giving us

\section{Maternity units-continued from page 838}

which have particular relevance to GP units. The GMSC supports the concept of one single information collecting system such as the Standard Maternity Information System currently under evaluation in the North of England.

Chamberlain et al, on behalf of the Children's Committee, argued in 1980: "There is much to recommend a randomised control trial of home delivery...." If home delivery then why not GP units? The Social Services Select Committee of the House of Commons supported confidential inquiries into perinatal mortality at district, regional, and national level which again would provide valuable information on this issue. ${ }^{6}$ One recent pilot study by Taylor et al has already demonstrated no difference in perinatal as much information as possible about what is happening in your own area.

The committee has also considered the financial implications of medical audit, but admits that at the present time no new money is likely to be made available for audit exercises. This will be pursued later when the concept of medical audit has been established.

Thus the liaison committee has decided to make certain recommendations which it is directing to all LMCs and college faculties for joint implementation; it will be assessing progress at its next meeting and we hope a significant step will have been taken towards establishing the concept of medical audit in general practice throughout the country by then. We hope you will accept the following recommendations, and take action on the first three of them. Any comments you care to make will be welcomed, and carefully considered; they should be addressed to either the secretary of the GMSC or the college, as appropriate.

\section{Recommendations}

(1) LMC secretaries are invited to make contact with their local RCGP faculty secretary, to discuss the appointment of a general practitioner or practitioners who will be responsible for medical audit in each National Health Service district (or equivalent in Scotland). Many LMCs will be responsible for more than one such district and it seems advisable to appoint someone for each district. Alternatively, faculty secretaries may themselves make contact with each LMC secretary within the faculty; but as several LMCs are likely to be within the area of each faculty, it is recommended that the initiative is taken by the LMC secretary. Full recognition should be given to the nominated doctors in this context by both LMC and RCGP faculty at their next meetings.

(2) Once recognised, the general practitioner(s) concerned should be responsible for identifying audit exercises already in operation in the district (or equivalent in Scotland). These doctors will also be responsible for disseminating information about what audit exercises are going on to all the general practitioners in the district and for advising on the formation of small groups for discussion where they do not already exist. (They may have available a report of the November symposium and references to various audit exercises which have already been documented.)

(3) LMC and faculty secretaries are asked to report back to the GMSC/RCGP Liaison Committee, via their parent organisations, on developments in the audit field at regular six-monthly intervals, so that the progress of the establishment of audit in general practice can be assessed by the liaison committee. Reports of any difficulties, including financial ones, in establishing the principles of medical audit, would be welcomed.

(4) The GMSC, in consultation with the college, will consider, in the light of experience, what approach to make in future regarding the funding of audit activities. 
are demanding over and above their medical condition they may be expected to pay for it; this should be done fairly.

Insured patients can be subdivided into two groups. Firstly, the reasonably well-off who have insured themselves for care both in this country and on foreign travel will expect both quality treatment and convenience to themselves, and they may be capable of and willing to top up fees to a greater extent than their benefit scale. So long as they are made aware of the full costs that they will encounter before they undertake the procedure, reasonable fees are quite legitimate. But considerable aggravation will be avoided if both they and their general practitioner know the true costs right from the start. It is important that the physician or surgeon who sees them initially explains that radiology, anaesthesia, pathology, and physiotherapy will be separately charged and what the true cost of beds, theatre charges, and drugs will be, so that the only hidden extras will be those they undertake themselves, such as telephone calls, television sets, etc.

The second subgroup, a growing and most important one, comprises those who are not in a position to top up their insurance policies. They are usually in group schemes, such as the electricians, policemen, firemen, etc, most of whom are paying their subscriptions out of their own pocket and will expect, barring accidents, to have their package within their insurance cover. They are usually undemanding patients, willing to have their operation at a convenient time and accepting the Marks and Spencers of private practice-namely, a goodquality job at a reasonable price. They are not interested in the Fortnum and Masons of multilingual nurses and telex and have no spare cash for frills. Even though the fee benefits may seem relatively low and in many cases the profit margin may be small, this group will provide an increase in the number of private patients so essential to the viability of the nursing homes on whom this practice depends. Because they cover a wide spectrum of social class they can help to remove for ever the idea that private medicine is the prerogative of the rich rather than the right of the provident and hardworking community.

The last group will include colleagues and their families, clergy, nursing staff, and other health workers. I always treat them as private patients and never send them a bill, whether they are insured or not. This ensures that any scheme that they belong to can be provided at the lowest possible cost. If they or their insurers send you a modest present this can be accepted but should in no way be expected. The fact that they have come to you is reward enough.

I have emphasised the fee-benefit scales of the provident societies but that does not mean that I regard them as awards from the Review Body. The provident societies are non-profitmaking organisations with no shareholders to pay who use their actuarial judgment to price their schemes so that private practice can not only exist but expand. Those who consistently overcharge will only kill the goose that lays the golden egg. Local branch managers can often help with higher benefits when a particularly complex procedure has been undertaken. In these circumstances it is wise to contact the branch giving the full facts on which to base a judgment. The various provident societies do not form a cartel: they are properly competing with each other and this in itself provides a considerable degree of safety.

\section{Safeguard of referral}

Should consultants accept patients direct? Except in exceptional circumstances the answer is no. The British system of referral by the principal in general practice to a consultant of his and the patient's choice is an important safeguard, in the same way that barristers accept briefs from solicitors. Far from increasing costs, it actually ensures a faster and more efficient service as well as providing perhaps the best known form of medical audit. There will be exceptional circumstances, in emergencies, in termination of pregnancy where there may be conflicting religious beliefs, and where the patient has no local doctor. Nevertheless, these occasions should be rare and the patient should be encouraged to register with a general practitioner as soon as possible. The GP should be kept fully informed of what has happened. I know there are those who advocate "trading direct." In my view, they are no longer behaving as consultants and I suspect their advocacy of this procedure is often because no one who knew them would refer cases to them anyway.

Newcomers to private practice should also remember that it carries no sick pay, study leave, or superannuation. It will also, after legitimate expenses, incur taxation. The advice of a good accountant who will advise on suitable insurance policies and book-keeping is essential from the start. His advice should be followed, remembering a consultant's knowledge of accountancy may be no better than the accountant's knowledge of surgery.

If the newcomer is ready to seek advice the experienced must be no less ready to give it. This will ensure the success of private practice for future generations. If the experienced consultant can also see the newcomer as a colleague rather than a competitor and in the early stages perhaps divert some private practice his way not only may they limit their own tax burden but they help a young colleague just when he needs it.

\section{References}

\section{${ }^{1}$ Anonymous. Br Med $\mathcal{F} 1980 ; \mathbf{2 8 0}: 202$.}

This paper was based on an address given to a teach-in on private practice organised by the Joint Consultants Committee and the Central Committee for Hospital Medical Services at BMA House on 16 January.

\section{Maternity units-continued from page 839}

regarding the recommendations of the Social Services Select Committee will do nothing to alleviate. ${ }^{8}$ Would it not be possible to write further to health authorities indicating that the matter is under review and perhaps emphasising that in any case the current policy is concerned with underusage of isolated units and not with the isolation alone?

In seeking a new look at the problem of safety and standards in different areas of intrapartum care, the GMSC is concerned only with the maintenance and further development of the highest possible standards for the entire community. It agrees in principle with the Social Services Select Committee that standards could improve in every sphere of obstetric practice and at the present time has these matters, as they relate to GP obstetricians, under active consideration. The GMSC agrees with much of the reply of the DHSS, differing strongly, where the DHSS takes a definite view, only on the question of GP maternity units. Having considered also the views of the RCGP, the GMSC will approve its final policy document in the next few weeks and will thereafter seek further discussions with the DHSS on the wider issues.

\section{References}

${ }^{1}$ Fedrick J, Butler NR. Intended place of delivery and perinatal outcome. Br Med f 1978; ; :763-5.

Ministry of Health. Report of the maternity services subcommittee. London: HMSO, 1959.

Butler NR, Bonham DG. Perinatal mortulity. The first report of the 1958 British Perinatal Mortaluty
Standing Maternity and Midwifery Advisory Com-
mittee. Domiciliary midwifery and maternity bed
needs. London: HMSO, 1970 .
Working Group of the Children's Committee. The
reduction of perinatal mortality and morbidity: a
discussion document. London, June 1979 .
'House of Commons Social Services Committee.
Perinatal and neonatal mortality. London: HMSO,
1980.
Taylor (jW, Edgar W, Taylor BA, Neal DG. How
safe is general practitioner obstetrics? Lancet
$1980 ;$ ii:1287-9.
Department of Health and Social Security. The reply
to the second report from the social services committee
on perinatal and neonatal mortality. Cmnd 8084.
London: HMSO, 1980 .

Other papers discussed during the preparation of the

rew $M$. Obstetric hospitals and GP units-the statistical record. 7 R Coll Gen Pract 1977;27:689-94

Marsh GN. Obstetric audit in general practice. Br Med $\mathcal{F}$ 1977; ii :1004-6.

Tew M. Facts, not assertions of belief. Health and Social Service Fournal 1980;12 September:1194-7.

Department of Health and Social Security. The future pattern of hospital provision in England. London: DHSS, 1980. 